Karsten Brüggemann, Mati Laur, Pärtel Piirimäe (dir.), Die baltischen Kapitulationen von 1710 : Kontexte, Wirkungen, Interpretationen

Köln/Weimar/Wien : Böhlau (Quellen und Studien zur baltischen

Geschichte, 23), 2014, 217 p., 34,90€

Mathieu Olivier

\title{
CpenEdition
}

Journals

Édition électronique

URL : http://journals.openedition.org/ifha/8155

DOI : $10.4000 /$ ifha. 8155

ISSN : 2198-8943

Éditeur

IFRA - Institut franco-allemand (sciences historiques et sociales)

Référence électronique

Mathieu Olivier, « Karsten Brüggemann, Mati Laur, Pärtel Piirimäe (dir.), Die baltischen Kapitulationen von 1710 : Kontexte, Wirkungen, Interpretationen », Revue de l'IFHA [En ligne], Date de recension, mis en ligne le 14 avril 2015, consulté le 22 septembre 2020. URL : http://journals.openedition.org/ifha/8155 DOl : https://doi.org/10.4000/ifha.8155

Ce document a été généré automatiquement le 22 septembre 2020.

(C)IFHA 


\section{Karsten Brüggemann, Mati Laur, Pärtel Piirimäe (dir.), Die baltischen Kapitulationen von 1710 : Kontexte, Wirkungen, Interpretationen}

Köln/Weimar/Wien : Böhlau (Quellen und Studien zur baltischen

Geschichte, 23), 2014, 217 p., 34,90€

Mathieu Olivier

Le lecteur francophone dispose d'une bibliographie relativement étoffée, dans sa langue maternelle, sur le règne de Pierre le Grand - un tsar qui avait su fasciner, au $\mathrm{XVIII}^{\mathrm{e}}$ siècle déjà, un Fontenelle ou un Voltaire. Reste que dans la plupart des histoires de la profonde mue de l'Empire russe au tournant des XVII et des XVIII $^{\mathrm{e}}$ siècles, les périphéries anciennes ou plus récemment acquises demeurent dans l'ombre du centre moscovite (puis pétersbourgeois). D'où l'intérêt de ce petit ouvrage édité par la très active Baltische Historische Kommission (voir Revue IHFA $\mathrm{n}^{\circ} 1$ ), les actes d'un colloque qui s'est tenu en 2010 à l'Université de Tartu (Dorpat) en Estonie. L'occasion en était le tricentenaire des capitulations de 1710, ces actes solennels par lesquelles les élites de ce que l'on appelait alors la Livonie troquèrent officiellement la suzeraineté suédoise contre la suzeraineté russe, dans le contexte de la "guerre nordique». Les neuf contributions au volume se répartissent en deux groupes. Trois d'entre elles replacent les actes de 1710 dans leur contexte. J. von Ungern-Sternberg revient - en partant du droit romain - sur la catégorie juridique de "capitulation", dans sa complexité et même, pourrait-on dire, sa plasticité. Tour à tour, Ralph Tuchtenhagen et Pärtel Piirimäe éclairent la signification de la rupture de 1710 à la lumière des formes de l'impérialisme suédois à la fin du XVII ${ }^{\mathrm{e}}$ siècle, et de la propagande déployée par Pierre le Grand à destination de l'Europe des premières Lumières.

Les six contributions restantes se penchent, en aval de 1710, sur les vicissitudes du régime finalement instable, perpétuellement renégocié et renégociable, qui s'installe en Livonie après la soumission à la Russie tsariste. Andres Andresen s'intéresse aux 
réformes concernant le statut et l'organisation confessionnelle des luthériens livoniens après 1710 - un domaine où la cour joue plutôt les arbitres entre différents groupes d'intérêts rivaux, au sein même de la société régionale. Mais la férule tsariste n'est pas toujours aussi distante: Mati Laur met en évidence les efforts de Catherine II pour réinterpréter en un sens très favorable les dispositions des textes de 1710 , quand elle ne choisit pas la voie de la contestation pure et simple du «contrat» ratifié quelques décennies plus tôt. $\mathrm{Au}$ siècle suivant, l'opinion livonienne elle-même se montrera divisée sur le degré de fidélité, plus ou moins littérale, qu'il convient de conserver visà-vis de ces textes, à l'heure de la contestation de la suprématie politique et culturelle des anciennes élites germano-baltes : c'est l'objet de la longue et dense contribution de Gert von Pistolhkors. Non moins dense et érudite, l'étude de l'historienne du droit estonienne Marju Luts-Sootak nous plonge dans la très complexe fabrique d'un droit régional livonien au XIX ${ }^{e}$ siècle, entre Saint-Pétersbourg, Riga, Reval et Dorpat - un processus dans lequel l'innovation juridique, adossée ou non au droit russe alors luimême en cours de formalisation, doit souvent avancer sous le masque d'une fidélité indéfectible, mais factice, aux textes de 1710, érigés en symboles et en égide, alors même que leur contenu juridique est en réalité imprécis et très lacunaire. Les deux dernières contributions, dues à Lars Björne et à Robert Schweitzer, parfaitement complémentaires, esquissent la comparaison qui s'imposait avec les modalités (elle aussi fluctuantes...) de l'autonomie finlandaise jusqu'à la veille de la Première Guerre mondiale.

On retiendra quelques idées forces de ces actes. Une nouvelle fois, on se rend compte que la norme juridique a un nez de cire. Le moindre des mérites du colloque n'est pas de déconstruire un peu plus encore l'idée, longtemps dominante dans l'historiographie germano-balte, selon laquelle les capitulations de 1710 avaient été la constitution quasi intangible, et bien réelle, des provinces baltes jusqu'à ce que la russification des dernières décennies du XIX ${ }^{e}$ siècle ne lui porte des coups fatals. Sur les bords de la Baltique comme ailleurs, on parlera bien plutôt d'invention de la tradition. Et même invention au carré, puisqu'on invente des normes absentes dans les textes de 1710, mais aussi un ordre juridique antérieur à 1710 qui, dans la cohérence idéale qu'on lui prête a posteriori, n'est qu'un fantasme historique. Deuxième enseignement majeur, nous semble-t-il : la fragilité de ce contractualisme des capitulations, obsolète parce que périmé, à distance de quelques décennies, par l'évolution de la société et des univers de références politiques, mais plus encore par le simple fait que les engagements souscrits par le nouveau maître ne sont jamais un bouclier efficace à long terme quand le rapport de force, par la suite, évolue dans un sens qui est par trop favorable à ce dernier. L'époque de Catherine II est symptomatique à cet égard. Troisième enseignement peut-être : les divisions toujours plus accusées qui fissurent, dès le $\mathrm{xvIII}^{\mathrm{e}}$ siècle (volontiers idéalisé comme le temps de la concorde par l'historiographie germano-balte de jadis), la société régionale - malgré les textes de 1710, ou même parfois à cause d'eux ou en tout cas autour de certaines de leurs clauses, passablement équivoques. C'est, au XVIII siècle, la noblesse territoriale contre le groupe des pasteurs. C'est surtout au siècle suivant, les « éveilleurs » des nations estonienne et lettone contre les tenants de l'ordre ancien, et de la prédominance de l'élite urbaine et rurale germano-balte.

$\mathrm{Au}$ total, un volume d'actes fort que l'on recommandera au lecteur germanophone, même s'il n'est pas un spécialiste de la région à l'époque moderne. Qu'on nous pardonne de terminer par une note plus critique : quelle qu'en soit la raison, l'absence 
d'historiens lettons peut sembler regrettable. On ne peut s'empêcher de penser que, de ce fait, le volume penche plus vers Reval que vers Riga. Dommage.

INDEX

Index chronologique : Ouvrages transpériodiques

Thèmes : Histoire du droit, Histoire des idées, Histoire sociale, Histoire des villes et des régions

\section{AUTEUR}

\section{MATHIEU OLIVIER}

Lycée Dumont-d'Urville, Toulon 